\title{
Does Psychoeducation Encourage Pregnant Women and Positively Influence the Relation between Mother and Baby: A Case-Control Study
}

\section{Nejla Gultekin}

Mersin Sehir Hospital, 33240 Toroslar/Mersin, Turkey

\begin{abstract}
Background: The emotional instability during pregnancy and the cultural negative feedback about normal vaginal delivery influence the tendency to cesarean section. The myth of vaginal delivery should be replaced with evidence based information which was given by professional persons. The coordinated educational program and pilates study in hospitals for pregnant women will encourage women during delivery and peurperal period.
\end{abstract}

Method: This study was designed as case-control for 1292 pregnant women which visit the obstetric clinic of Mersin Sehir Hospital, Turkey. Case group have 421 and control group have 871 patients. The first goal was for defining of fear about vaginal birth, mode of delivery, satisfaction from pregnancy and delivery, lastly flashback after birth. In addition, secondary goal was determining the unnecessary visit of obstetric clinic in postpartum period, breastfeeding ratio, planning of next pregnancy and choosing of normal vaginal delivery in future birth.

Result: Obviously, the midwife intervention encourages women to have happy, satisfied and successfull pregnancy, delivery and puerperium. However the effectiveness of education program shouldn't be measured with the cesarean section ratio and the aim of education shouldn't be forcing of pregnant women to the normal vaginal delivery. It should be encouraged by programme.

Conclusion: The statistical measurements of emotions will be represented with biases. Besides, the midwife intervention and pilates were seem to be successful programme for pregnant women to neglect the negative effects of delivery without changing of ceaserean numbers.

\section{Introduction}

In Turkey, the increasing cesarean section $(\mathrm{C} / \mathrm{S})$ ratio is an universal problem. Especially in south eastearn region and in lower social economics part of Turkey, $\mathrm{C} / \mathrm{S}$ ratio is rised steadily. Although the epidural vaginal delivery protocol, the lack of practical experience of anesthesia and the overcrowded hospitals limit the capability of epidural anesthesia. In contrast to European and American hospitals, the cost of $\mathrm{C} / \mathrm{S}$ does not differ in Turkey even though in private hospitals from the normal vaginal delivery (NVD). For this reason, the increased elective $\mathrm{C} / \mathrm{S}$ ratio can't be decreased especially in primary pregnancy. The fearness of vaginal delivery that is emphasized with cultural factors is a nightmare in pregnant women. The satisfaction of pregnancy and the being a maternity or family is not considered. Poor emotional health is associated with increasing childbirth fear and risk of depression, birth trauma and inability to interact positively with baby and meet infant development needs and can be stressor in couple relationship [1-11]. By the improving of technology, the social media aggravated this fear with some videos of normal vaginal delivery.

In obstetric clinics at Mersin Sehir Hospital, we try to give education by mid-wive intervention and the opportunity of plates with coach. The aim of this organization to emphasize the nature of vaginal birth and the capability of mother vaginal delivery with less fear, more controlled body and the knowledge about delivery and baby.

This study is a retrospective case-control study among women that visit obstetric clinics in Mersin Sehir Hospital, Turkey. The case and control groups have been choosen randomly. The first goal is the measurement of fear about vaginal birth, and prefered mode of delivery before and after the midwife intervention. The tendency to the $\mathrm{C} / \mathrm{S}$ because of fearfull pregnant women may be decreased by midwife intervention. The pregnant women with childbirth fear more often prefer a C/S [12-14]. Not only the lowering C/S ratio is our goal, but also the satisfaction of pregnancy, vaginal delivery and lowering flashback are in our first goal. The maternity is a sacred phase of human being and it shouldn't be interrupted with unsatisfied experience in delivery. Secondary goal of our study was the number of visit of obstetric clinic in postpartum period. The mother wonders that something is wrong with baby or herself because of unsatisfied delivery. The effective and continuation of breastfeeding, the programming of future pregnancy in first month and the planning of next pregnancy with normal vaginal delivery are also secondary goals. Infact, unsatisfied delivery causes bad flashback which is the reason of discontinuation of breastfeeding. The planning next pregnancy in the puerperal period with vaginal delivery is affected with bad experience. Even though the future pregnancy is planned as $\mathrm{C} / \mathrm{S}$.

\section{Methods}

This is retrospective case-control study with sample size of 482 pregnant women in case group and 949 pregnant women in control group. All women was in their first pregnancies the 12 women from case group were discontinued the education and 42 women were undergo to the $\mathrm{C} / \mathrm{S}$ because of fetal distress or cephalopelvic disproportion. 8 women from case group were unreachable after the

*Corresponding Author: Dr. Nejla Gultekin, Mersin Sehir Hospital, 33240 Toroslar/Mersin, Turkey; E-mail: nejlagultekin@yahoo.com

Citation: Gultekin N (2018) Does Psychoeducation Encourage Pregnant Women and Positively Influence the Relation between Mother and Baby: A CaseControl Study. Int J Gynecol Clin Pract 5: 143. https://doi.org/10.15344/23944986/2018/143

Copyright: (c) 2018 Gultekin. This is an open-access article distributed under the terms of the Creative Commons Attribution License, which permits unrestricted use, distribution, and reproduction in any medium, provided the original author and source are credited. 
Citation: Gultekin N (2018) Does Psychoeducation Encourage Pregnant Women and Positively Influence the Relation between Mother and Baby: A CaseControl Study. Int J Gynecol Clin Pract 5: 143. https://doi.org/10.15344/2394-4986/2018/143

Page 2 of 4

delivery. In the control group, 23 women were excluded because of cholestasis and preeclampsia, 43 patients were lost during pregnancy or postpartum period. 12 women refused the filling of WDEQ-A questionnaire. To summarize; the pregnant women between 16-40 years old first pregnancy was included to study. Those women were integrated in midwife intervention in 3 sessions and 3-6 times pilates sessions with coach in obstetric clinics of Mersin Sehir Hospital.

\section{Data Collection and Measurements}

The completion of questionnaire about demographic characteristics was asked to women. The WDEQ-A was used to measure the antenatal childbirth fear [15]. Women scoring high childbirth fear $(>66)$ were randomised to the case and control group [16]. The other midwife intervention was done after 1 month of delivery in case and control groups.

\section{Statistic Analysis}

The study was a retrospective case-control study among patients in the obstetric clinics, at Mersin Sehir Hospital. The data was analyzed with SPSS (Statistical Package for Social Sciences) for Windows 22.0 programme. The analysis of data was delineated in numbers and percentages. The relation between the group variations was analyzed ki-square test.

\section{Result}

The estimated child birth fear is $6-10 \%$ of all pregnancy which is common among the nulliparous as in parous [17-20]. This study is the measurements of subjective findings. The absence of recall and the analysis of emotion will cause the biases in some degree. But the bad experience during the pregnancy and delivery may affect the whole women's life. We try to standardized the education programme

\begin{tabular}{|c|c|c|c|c|c|c|c|}
\hline & \multicolumn{4}{|c|}{ Groups } & & & \multirow{3}{*}{$\mathrm{X}^{2} / \mathrm{p}$} \\
\hline & \multicolumn{2}{|c|}{ Case } & \multicolumn{2}{|c|}{ Control } & \multicolumn{2}{|c|}{ Total } & \\
\hline & $\mathrm{n}$ & $\%$ & $\mathrm{n}$ & $\%$ & $\mathrm{n}$ & $\%$ & \\
\hline Normal vaginaldelivery & 308 & $\% 73,2$ & 444 & $\% 51,0$ & 752 & $\% 58,2$ & \multirow{3}{*}{$\begin{array}{l}X^{2}=57,412 \\
p=0,000\end{array}$} \\
\hline Cesareansection & 113 & $\% 26,8$ & 427 & $\% 49,0$ & 540 & $\% 41,8$ & \\
\hline Total & 421 & $\% 100,0$ & 871 & $\% 100,0$ & 1292 & $\% 100,0$ & \\
\hline
\end{tabular}

Table 1: The Comparision of Normal Vaginal Delivery RatioBetweenGroups.

The normal vaginal delivery ratio as we expected was higher in case group (73.2\%) than the control (51.0\%) statistically $\left(\mathrm{X}^{2}=57,412 ; \mathrm{p}=0,000<0.05\right)$.

\begin{tabular}{|c|c|c|c|c|c|c|c|}
\hline \multirow[t]{3}{*}{ Satisfaction from the Pregnancy } & \multicolumn{4}{|c|}{ Groups } & & & \multirow[t]{3}{*}{$\mathrm{X}^{2} / \mathrm{p}$} \\
\hline & \multicolumn{2}{|c|}{ Case } & \multicolumn{2}{|c|}{ Control } & \multicolumn{2}{|c|}{ Total } & \\
\hline & $\mathrm{n}$ & $\%$ & $\mathrm{n}$ & $\%$ & $\mathrm{n}$ & $\%$ & \\
\hline Satisfaction & 371 & $\% 88,1$ & 548 & $\% 62,9$ & 919 & $\% 71,1$ & \multirow{3}{*}{$\begin{array}{l}\mathrm{X}^{2}=87,820, \\
\mathrm{p}=0,000\end{array}$} \\
\hline Non- satsifaction & 50 & $\% 11,9$ & 323 & $\% 37,1$ & 373 & $\% 28,9$ & \\
\hline Total & 421 & $\% 100,0$ & 871 & $\% 100,0$ & 1292 & $\% 100,0$ & \\
\hline
\end{tabular}

Table 2: The SatisfactionfromthePregnancy in Case and Control Groups.

By the midwife intervention and pregnancy and pilates coach educational program the satisfaction from the pregnancy among the pregnant women was statistically higher in case $(88.1 \%)$ than the control group $(62.9 \%),\left(X^{2}=87,820 ; p=0,000<0.05\right)$.

\begin{tabular}{|c|c|c|c|c|c|c|c|}
\hline \multirow[t]{3}{*}{ Satisfaction from Delivery } & \multicolumn{4}{|c|}{ Groups } & & & \multirow[t]{3}{*}{$\mathrm{X}^{2} / \mathrm{p}$} \\
\hline & \multicolumn{2}{|c|}{ Case } & \multicolumn{2}{|c|}{ Control } & \multicolumn{2}{|c|}{ Total } & \\
\hline & $\mathrm{n}$ & $\%$ & $\mathrm{n}$ & $\%$ & $\mathrm{n}$ & $\%$ & \\
\hline Satisfaction & 274 & $\% 65,1$ & 304 & $\% 34,9$ & 578 & $\% 44,7$ & \multirow{3}{*}{$\begin{array}{l}X^{2}=104,567 \\
p=0,000\end{array}$} \\
\hline Non- satisfaction & 147 & $\% 34,9$ & 567 & $\% 65,1$ & 714 & $\% 55,3$ & \\
\hline Total & 421 & $\% 100,0$ & 871 & $\% 100,0$ & 1292 & $\% 100,0$ & \\
\hline
\end{tabular}

Table 3: The Satisfaction from Normal Vaginal Delivery.

The similar result was found in the stasifaction from the normal vaginal delivery. The ratio was higher in case group (65.1\%) than the control group $(34.9 \%),\left(\mathrm{X}^{2}=104,567 ; \mathrm{p}=0,000<0.05\right)$ statistically.

\begin{tabular}{|c|c|c|c|c|c|c|c|}
\hline \multirow[t]{3}{*}{ Flashback } & \multicolumn{4}{|c|}{ Groups } & & & \multirow[t]{3}{*}{$\mathrm{X}^{2} / \mathrm{p}$} \\
\hline & \multicolumn{2}{|c|}{ Case } & \multicolumn{2}{|c|}{ Control } & \multicolumn{2}{|c|}{ Total } & \\
\hline & $\mathrm{n}$ & $\%$ & $\mathrm{n}$ & $\%$ & $\mathrm{n}$ & $\%$ & \\
\hline Flashback & 206 & $\% 48,9$ & 775 & $\% 89,0$ & 981 & $\% 75,9$ & \multirow{3}{*}{$\begin{array}{l}X 2=249,043 \\
p=0,000\end{array}$} \\
\hline No flashback & 215 & $\% 51,1$ & 96 & $\% 11,0$ & 311 & $\% 24,1$ & \\
\hline Total & 421 & $\% 100,0$ & 871 & $\% 100,0$ & 1292 & $\% 100,0$ & \\
\hline
\end{tabular}

Table 4: The Flashback of Normal Vaginal Delivery.

The normal vaginal delivery flashback was statistically measured and the ratio was lower in case group (48.9\%) than the control $(89.0 \%),\left(\mathrm{X}^{2}=249,043 ; \mathrm{p}=0,000<0.05\right)$. 
Citation: Gultekin N (2018) Does Psychoeducation Encourage Pregnant Women and Positively Influence the Relation between Mother and Baby: A CaseControl Study. Int J Gynecol Clin Pract 5: 143. https://doi.org/10.15344/2394-4986/2018/143

Page 3 of 4

for pregnant women to increase the normal vaginal delivery (NVD) numbers, be satisfied from pregnancy and NVD, to reduce the unnecessary recurrent visit of obstetric clinics, to encourage breast feeding, to support families for their future pregnancy.

The study determined that the educational programme may encourage the pregnant women in the delivery room (as shown in Table 1). Instead, the cesarean ratio didn't changed especially in planned pregnancy (as in Table 8). Especially in planned pregnancy, delivery route was chosen as cesarean section even in educated pregnant women. Besides, the midwife intervention satisfied women from pregnancy period and NVD (Table 2 and Table 3). Women felt the being mother during delvery by comparing with control groups. The nightmare or flashback recall during one month of peurperium was decreased by midwife intervention (Table 4). For this reason, the traumatic part of the delivery and pregnancy was regreded by the educational programme.
In the control group, the recurrent unnecessary obstetric clinic visit was detected because of questions about delivery and baby (table 5). In those visit the emotionally unsatisfied, scarred and doubtfull mother's was observed. By means of midwife intervention, those traumatic factors was elected and happy mothers with happy babies were created. The emotional satisfaction effects the breast feeding positively, in the educated pregnant women the future plan and the happiness of being mother was showed by the high ratio of planning next pregnancy in contrast to control group (Table 7). Interestingly, the $\mathrm{C} / \mathrm{S}$ ratio was not affected by the education, it was certain that, even though midwife intervention did not positively rised the desire of normal vaginal delivery (Table 8).

Surely, the case group didn't want to undergo NVD in next pregnancy. The reason of this may be, although the education, traumatic pain of delivery which wasn't decreased by the midwife intervention. Besides the positive effect of educational programme, the reality of normal vaginal delivery may have negatif consequences.

\begin{tabular}{|c|c|c|c|c|c|c|c|}
\hline \multirow[t]{3}{*}{ Recurrent Visit Of Obstetric Clinic } & \multicolumn{4}{|c|}{ Groups } & & & \multirow[t]{3}{*}{$\mathrm{X}^{2} / \mathrm{p}$} \\
\hline & \multicolumn{2}{|c|}{ Case } & \multicolumn{2}{|c|}{ Control } & \multicolumn{2}{|c|}{ Total } & \\
\hline & $\mathrm{n}$ & $\%$ & $\mathrm{n}$ & $\%$ & $\mathrm{n}$ & $\%$ & \\
\hline Recurrentvisit & 164 & $\% 39,0$ & 566 & $\% 65,0$ & 730 & $\% 56,5$ & \multirow{3}{*}{$\begin{array}{l}X^{2}=78,232 \\
p=0,000\end{array}$} \\
\hline Plannedvisit & 257 & $\% 61,0$ & 305 & $\% 35,0$ & 562 & $\% 43,5$ & \\
\hline Total & 421 & $\% 100,0$ & 871 & $\% 100,0$ & 1292 & $\% 100,0$ & \\
\hline
\end{tabular}

Table 5: The Recurrent Visit Of Obstetric Clinic.

The unnecessary reccurrent visit of obstetric clinic was lower in case (39.0\%) than the control group (65.0\%) by statistical importance $\left(\mathrm{X}^{2}=78,232 ; \mathrm{p}=0,000<0.05\right)$.

\begin{tabular}{|c|c|c|c|c|c|c|c|}
\hline \multirow[t]{3}{*}{ Breast Feeding } & \multicolumn{4}{|c|}{ Groups } & & & \multirow[t]{3}{*}{$\mathrm{X}^{2} / \mathrm{p}$} \\
\hline & \multicolumn{2}{|c|}{ Case } & \multicolumn{2}{|c|}{ Control } & \multicolumn{2}{|c|}{ Total } & \\
\hline & $\mathrm{n}$ & $\%$ & $\mathrm{n}$ & $\%$ & $\mathrm{n}$ & $\%$ & \\
\hline Breast feeding & 400 & $\% 95,0$ & 714 & $\% 82,0$ & 1114 & $\% 86,2$ & \multirow{3}{*}{$\begin{array}{l}X^{2}=40,609 \\
p=0,000\end{array}$} \\
\hline No breast feeding & 21 & $\% 5,0$ & 157 & $\% 18,0$ & 178 & $\% 13,8$ & \\
\hline Total & 421 & $\% 100,0$ & 871 & $\% 100,0$ & 1292 & $\% 100,0$ & \\
\hline
\end{tabular}

Table 6: The Ratio of Breast Feeding.

The ratio of breast feeding was higher in case group (95.0\%), although the percentage was $82.0 \%$ in control group. The statistical importance was determined between groups $\left(\mathrm{X}^{2}=40,609 ; \mathrm{p}=0,000<0.05\right)$.

\begin{tabular}{|c|c|c|c|c|c|c|c|}
\hline \multirow[t]{3}{*}{ Planning Future Pregnancy } & \multicolumn{4}{|c|}{ Groups } & & & \multirow[t]{3}{*}{$\mathrm{X}^{2} / \mathrm{p}$} \\
\hline & \multicolumn{2}{|c|}{ Case } & \multicolumn{2}{|c|}{ Control } & \multicolumn{2}{|c|}{ Total } & \\
\hline & $\mathrm{n}$ & $\%$ & $\mathrm{n}$ & $\%$ & $\mathrm{n}$ & $\%$ & \\
\hline Planning & 135 & $\% 32,1$ & 148 & $\% 17,0$ & 283 & $\% 21,9$ & \multirow{3}{*}{$\begin{array}{l}X^{2}=37,703 \\
p=0,000\end{array}$} \\
\hline Non-planning & 286 & $\% 67,9$ & 723 & $\% 83,0$ & 1009 & $\% 78,1$ & \\
\hline Total & 421 & $\% 100,0$ & 871 & $\% 100,0$ & 1292 & $\% 100,0$ & \\
\hline
\end{tabular}

Table 7: The Planning Future Pregnancy.

In the case, the planning of future pregnancy was $(32.1 \%)$ more than the control group $(17.0 \%),\left(X^{2}=37,703 ; p=0,000<0.05\right)$.

\begin{tabular}{|c|c|c|c|c|c|c|c|}
\hline \multirow[t]{3}{*}{ Prefering C/S in Planned Pregnancy } & \multicolumn{4}{|c|}{ Groups } & & & \multirow[t]{3}{*}{$\mathrm{X}^{2} / \mathrm{p}$} \\
\hline & \multicolumn{2}{|c|}{ Case } & \multicolumn{2}{|c|}{ Control } & \multicolumn{2}{|c|}{ Total } & \\
\hline & $\mathrm{n}$ & $\%$ & $\mathrm{n}$ & $\%$ & $\mathrm{n}$ & $\%$ & \\
\hline Prefering $\mathrm{C} / \mathrm{S}$ & 113 & $\% 26,8$ & 49 & $\% 5,6$ & 162 & $\% 12,5$ & \multirow{3}{*}{$\begin{array}{l}X^{2}=116,483 \\
p=0,000\end{array}$} \\
\hline Prefering NVD & 308 & $\% 73,2$ & 822 & $\% 94,4$ & 1130 & $\% 87,5$ & \\
\hline Total & 421 & $\% 100,0$ & 871 & $\% 100,0$ & 1292 & $\% 100,0$ & \\
\hline
\end{tabular}

Table 8: The Prefering C/S in Planned Pregnancy.

The cesarean section option in the planned future pregnancy was suprisingly higher in caseg roup (26.8\%) than the control group $(5.6 \%),(\mathrm{X} 2=116,483 ; \mathrm{p}=0,000<0.05)$. 
Citation: Gultekin N (2018) Does Psychoeducation Encourage Pregnant Women and Positively Influence the Relation between Mother and Baby: A CaseControl Study. Int J Gynecol Clin Pract 5: 143. https://doi.org/10.15344/2394-4986/2018/143

\section{Conclusion}

Midwife intervention should be professionally given to all pregnant women to encourage women for healthy mothers and babies but the $\mathrm{C} / \mathrm{S}$ rate shouldn't be designed by the educational programme.

\section{Competing Interests}

The author declare no competing interests.

\section{References}

1. Areskog B, Uddenberg N, Kjessler B (1984) Postnatal emotional balance in women with and without antenatal fear of childbirth. J Psychosom Res 28 213-220.

2. Soderquist J, Wijma B, Thorbert G, Wijma K (2009) Risk factors in pregnancy for posttraumatic stress and depression after childbirth. BJOG 116: 672-680.

3. Ryding EL, Wijma B, Wijma K, Rhydhstrom H (1998) Fear of childbirth during pregnancy may increase the risk of emergency caserean section. Acta Obstet Gynecol Scand 77: 542-547.

4. Raisanen S, Lehto S, Nielsen H, Gissler M, Kramer M, et al. (2013) Fear of childbirth predicts postpartum depression: a population-based analysis of 511422 singleton births in Finland. BMJ Open 3: e004047.

5. Beck CT (2004) Birth trauma: In the eye of the beholder. Nurs Res 53: 28-35

6. Beck C, Watson S (2010) Subsequent childbirth after a previous traumatic birth. Nurs Res 59: 241-249.

7. Creedy D, Shochet I, Horsfall J (2000) Childbirth and the development of acute trauma symptoms: incidence and contributing factors. Birt 27:104111.

8. Ryding E, Persson A, Onell C, Kvist L (2003) An evaluation of midwives' counseling of pregnant women in fear of childbirth. Acta Obstet Gyneco Scand 82: 10-17.

9. Kingston D, Tough S (2014) Prenatal and postnatal maternal mental health and school-Age child development: a systematic review. Matern Child Health J 18: 1728-1741.

10. Bailham $D$, Joseph $S$ (2003) Post-traumatic stress following childbirth: A review of the emerging literature and directions for research and practice. Psychol Health Med 8: 159-168.

11. Nicholls K, Ayers S (2007) Childbirth-related post-traumatic stresss disorder in couples: A qualitative study. Br J Health Psychol 12: 491-509.

12. Nieminen K, Stephansson O, Ryding EL (2009) Women's fear of childbirth and preference for cesarean section -a cross-sectional study at various stages of pregnancy in Sweden. Acta Obstet Gynecol Scand 88: 807-813.

13. Ryding EL, Lukasse M, Parys AV, Wangel A, Karro H, et al. (2015) Fear of childbirth and risk of Caesarean section: a cohort study in six European countries. Birth 42: 48-55.

14. Johnson $R$, Slade $P$ (2002) Does fear of childbirth during pregnancy predict emergency caesarean section? BJOG 109: 1213-1221.

15. Wijma K, Wijma B, Zar M (1998) Psychometric aspects of the W-DEQ; a new questionnaire for the measurement of fear of childbirth. J Psychosomatic Obstet Gynecol 19: 84-97.

16. Jennifer F, Jocelyn T, Jenny G, Debra KC, Anne B, et al. (2015) Effects of a midwife psycho-education intervention to reduce childbirth fear on women's birth outcomes and postpartum psychological wellbeing. BMC Preg Childbirth 15: 284

17. Melender HL (2002) Experience of fears associated with pregnancy and childbirth: a study of 329 pregnant women. Birth 29: 101-111.

18. Rouhe H, Salmole Aro K, Halmesmaki E, Saisto T (2009) Fear of childbirth according to parity, gestational age and obstetric history. BJOG 116: 67-73.

19. Neiminen K, Stephansson O, Ryding EL (2009) Women's fear of childbirth and preference for cesarean section- a cross sectional studyat various stage of pregnancy Sweden. Acta Obstet Gnecol Scand 88: 807-813.

20. Fuglenes D, Aes E, Botten G, Oian P, Sonbo Kristiansen I, et al. (2005) Why do some pregnant women prefer cesarean? The infleunce of parity, delivery experience and fear. Am J Obstet Gynecol 205: 45e1-9. 